Este libro forma parte del acervo de la Biblioteca Jurídica Virtual del Instituto de Investigaciones Jurídicas de la UNAM

\title{
LA DISGUSIÓN FILOSÓFICA SOBRE LA GUÍA BIOÉTICA
}

\author{
Juan A. CRUz PARcero \\ SUMARIO: I. Introducción. II. La discusión filosófica: afirmaciones y ar- \\ gumentos.
}

\section{INTRODUCCIÓN}

El 13 de abril se publicó en la página del Consejo de Salubridad General (CSG) un proyecto de Guía Bioética, que luego de unas semanas de intensas discusiones se aprobaría por los vocales del CSG el 30 de abril con el nombre de Guía Bioética para Asignación de Recursos Limitados de Medicina Crítica en Situación de Emergencia. ${ }^{1}$ Durante las dos semanas que transcurrieron de la publicación a su aprobación tuvo lugar una viva discusión que sirvió para mejorar el proyecto. Pocos documentos públicos han sido discutidos con tanta vehemencia en tan poco tiempo, pero no era para menos, pues hablar de la vida y la muerte en tiempos de pandemia, es un asunto espinoso.

El interés se debió no sólo por la importancia del tema, sino también al amarillismo con que algunos medios y opinadores se ocuparon de él. El periódico El Universal publicó a ocho columnas una nota sobre la Guía cuyo titular rezaba: "Priorizarán a jóvenes en atención de COVID-19", y añadía: "Se pondrán por arriba de adultos mayores". ${ }^{2}$ Muchas reacciones en medios surgieron a partir de este encabezado. Hay que decir que la nota no era mala, tenía algunas imprecisiones, pero el encabezado distorsionaba el contenido de la Guía. Muchas voces indignadas se alzaron, algunas ni siquiera leyeron la nota del diario y mucho menos el proyecto, pero pronto las redes sociales hablaban de políticas eugenésicas, fascistas, discriminatorias

1 Se puede consultar en: http://wrere.csg.gob.mx/descargas/pdf/index/informacion_relevante/ GuiaBioeticaTriaje_30_Abril_2020_7pm.pdf.

2 La noticia apareció el 14 de abril del 2020; consultable en: https://wrere.eluniversal.com. $\mathrm{mx} /$ nacion/priorizar-jovenes-sobre-tercera-edad-recomiendan-medicos-por-covid-19. 
Este libro forma parte del acervo de la Biblioteca Jurídica Virtual del Instituto de Investigaciones Jurídicas de la UNAM

de los adultos mayores, etc. Sergio Aguayo, por citar otro ejemplo, tanto en el programa de Carmen Aristegui como por su cuenta de Twitter, difundió la idea de que no habrá ventiladores para las personas de la tercera edad, que para la $4 \mathrm{~T}$ la tercera edad es desechable. ${ }^{3}$ Margarita Zavala, de modo más reflexivo curiosamente, también señaló lo que consideró cinco fallas de la Guía. ${ }^{4}$

Hay que reconocer que la aparición del proyecto de Guía generó confusión, en parte justificada, porque no se aclaraba en la misma página del CSG que se trataba de un documento para discusión, cosa que inmediatamente tuvo que aclararse. También hay que reconocer que la redacción favoreció ciertas suspicacias de algunos, aunque pienso que fue más la mala fe o la frivolidad las que lograron tergiversar lo que se decía. Con todo y que el texto no era del todo claro en algunos aspectos, la idea era precisamente discutirlo. Claro que en un escenario politizado y polarizado los participantes adoptan distintas actitudes. Por un lado, varias personas e instituciones enviaron al CSG cartas explicando sus preocupaciones por ciertos puntos y haciendo recomendaciones, mientras que organismos públicos y ONGs buscaron interlocución con el grupo que participó en la redacción de la Guía. Se tuvo una importante retroalimentación con la Comisión de Derechos Humanos de la Ciudad de México (CDHCDMX), la Organización Panamericana de la Salud (OPS/OMS México), el Consejo Nacional para Prevenir la Discriminación (Conapred), el Consejo para Prevenir y Eliminar la Discriminación de la Ciudad de México (Copred) y algunos Consejos o asociaciones de médicos y de hospitales. Lo mismo ocurrió con algunas de las organizaciones vocales del CSG, como la Academia Nacional de Medicina A.C., y la Academia Mexicana de Cirugía A.C. Muchos entendieron que la Guía era necesaria, relevante en las circunstancias que se preveían en ella, y se sumaron a construir una mejor versión.

Por otro lado, hubo quienes asumieron una actitud de confrontación y denuncia. Se vale, no hay nada de malo en ello. Habrá que decir que en la comisión de redacción de la Guía se tomaron en consideración también varias de las opiniones de este tipo, por más que estuvieran mezcladas con argumentos ad hominem, insultos o exageraciones. La Guía Bioética no es por sí misma un trabajo académico, sino un instrumento de política pública y por su misma naturaleza el debate generado era inevitablemente político,

3 Puede verse en: https://aristeguinoticias.com/1404/mexico/daran-a-jovenes-ventilador-y-no-aadulto-mayor-en-caso-de-que-haya-que-elegir-guia-bioetica/.

4 Puede consultarse en: https://wrere.eluniversal.com.mx/opinion/margarita-zavala/la-famosaguia-bioetica. 
Este libro forma parte del acervo de la Biblioteca Jurídica Virtual del Instituto de Investigaciones Jurídicas de la UNAM

sujeto a las condiciones de polarización e intereses que pueden surgir en ese ámbito. ${ }^{5}$ Aunque convendría precisar que quienes nos involucramos en la redacción, no lo hicimos por ninguna forma de militancia política de tipo partidista, incluso se podría decir que, a pesar de que algunos miembros del grupo de redactores han sido abiertamente críticos del gobierno, se consideró que había que colaborar con los esfuerzos que se estaban haciendo para enfrentar la pandemia.

$\mathrm{Al}$ tratarse de una Guía bioética, muchos y muchas filósofas participaron en el debate, tanto del lado de quienes cooperaron como del lado de quienes se opusieron. Los filósofos se movilizaron, escribieron en columnas de periódicos, en redes sociales, en televisión y radio; el Observatorio Filosófico de México A. C., publicó una carta repudiando la Guía. Hay que decir que los formatos de opiniones en columnas en medios o cartas de rechazo no son precisamente la mejor forma de desarrollar argumentos filosóficos; muchas veces las opiniones expresadas no consiguen, por cuestiones de espacio o de tiempo, desarrollar los argumentos de que se dispone. Con todo, es de celebrar que hayan participado en un debate público de interés general.

En este trabajo me propongo hacer una revisión de las críticas filosóficas que se le hicieran al proyecto de Guía, con la finalidad de continuar una discusión filosófica sobre diversos temas que surgieron y sobre los que vale la pena profundizar. Ahora ya alejados del ambiente de esas dos semanas convulsas, es sano continuar la discusión en foros académicos. Desde luego que la discusión debería seguir también respecto de otros temas relacionados con la Guía para saber si sirvió o no, qué tanto, los problemas que surgieron para implementarla, dónde hubo necesidad de hacer triaje, cómo se hizo, etc. Todo ello merece la atención de especialistas. En el siguiente apartado analizaré siete críticas al proyecto y presentaré algunos argumentos en contra de éstas. Se trata de continuar un debate filosófico de temas que desde luego no pueden agotarse en este trabajo.

\section{LA DISCUSIÓN FILOSÓFICA: AFIRMAGIONES Y ARGUMENTOS}

No todas las objeciones al proyecto de Guía fueron de índole filosófica, algunas, como ya mencioné, fueron de carácter político, otras versaron sobre los criterios médicos, otras más sobre cuestiones fácticas o sobre la pertinencia. Yo me ocuparé aquí de algunas de las afirmaciones o argumentos que atacaban

5 Hubo quienes leyeron la publicación de la Guía como una confrontación interna entre el Secretario de Salud y el Subsecretario de Prevención y Promoción de la Salud. Por ejemplo, véase en: https://wwre.eluniversal.com.mx/opinion/salvador-garcia-soto/jugando-ser-dios. 
Este libro forma parte del acervo de la Biblioteca Jurídica Virtual del Instituto de Investigaciones Jurídicas de la UNAM

los principios morales o bioéticos en los que se basaba el proyecto de Guía. De una revisión de las opiniones críticas vertidas quiero resaltar siete cuestiones:

a) La irrelevancia de la filosofía para decidir cuestiones de triaje.

b) La negación del dilema ético entre salvar vidas (o proteger derechos) en situaciones de escasez de recursos.

c) La afirmación de que el principio de salvar el mayor número de vidas posible, por ser utilitarista (capitalista o neoliberal), es incorrecto e injustificado.

d) La idea de que hay vidas humanas más valiosas que otras y que ello debe contar en el triaje.

e) La afirmación de que la elección de priorizar a quién atender y a quién no, viola derechos humanos o implica un homicidio.

f) La afirmación de que la Guía discrimina a los mayores de edad.

g) La afirmación de que decidir aleatoriamente (por azar) es injustificable.

\section{Negar la relevancia filosófica o moral en el triaje}

Casi todos los filósofos consideraron que el tema era relevante filosófica y moralmente (éticamente), ${ }^{6}$ aunque mantuvieran algunos desacuerdos al respecto. Ciertamente, los problemas éticos durante una pandemia van más allá del problema de cómo asignar recursos en situaciones de escasez y, particularmente, más allá de cómo asignar recursos de medicina crítica. Pero que ello sea así, no implica que el tema de una guía bioética de asignación de recursos de medicina crítica sea irrelevante.

Sin embargo, María Antonia González Valero y Rosaura Martínez Ruiz ${ }^{7}$ consideraron que la filosofía no debía entrometerse en asuntos de este tipo. Aquí su postura:

La pregunta que nos acecha es si la filosofía tiene lugar en esta discusión, si tiene algo que decir en relación a criterios médicos para el cuidado y supervivencia en esta enfermedad.

6 Utilizaré moral y ética como sinónimos. Para una buena y breve explicación sobre sus posibles diferencias entre los filósofos puede verse el reciente texto de Gustavo Ortiz Millán, "Entre la ética y la moralidad", Nexos, 1o. de junio de 2020, consultable en: https://nexos.com. $m x / ? p=42658$.

7 "Triaje. Decir lo éticamente indecible", El Universal, 22 de abril de 2020, consultable en: https://wreweluniversal.com.mx/opinion/maria-antonia-gonzalez-valerio-y-rosaura-martinez-ruiz/ triaje-decidir-lo-eticamente. 
Este libro forma parte del acervo de la Biblioteca Jurídica Virtual del Instituto de Investigaciones Jurídicas de la UNAM

Cualquier parámetro que se establezca para decidir qué vidas valen más que otras es éticamente injustificable y debe ser cuestionado y resistido. No se puede normalizar ninguna lógica para decidir quién vive y quién muere. Hacer tablas con números, reducir la existencia al valor numérico y fingir con ella cierta "neutralidad" no puede ser labor de la filosofía.

¿Hay criterios éticos para guiar la decisión soberana? ¿El filósofo será verdugo? ¿La filosofía puede construir la justificación de la decisión por principio más injusta e inmoral? No, imperativamente no. El quehacer filosófico tiene que argumentar en contra de la instrumentación de un supuesto criterio universal para tomar la decisión de quién vive y quién muere.

La guía que fue presentada no tiene nada de bioética. Es un instrumento ideológico con el que no podemos concordar. La justificación que sostiene que este escenario es análogo al de las guerras y que en las guerras esas difíciles decisiones hay que tomarlas, es una prístina muestra de la perversión de la razón que naturaliza la violencia y se olvida de que la decisión soberana es la que por principio moral hay que resistir y denunciar.

Las autoras rechazan tajantemente que la filosofía pueda justificar algo en este tipo de cuestiones. Sostienen una idea radical de que sobre cuestiones de vida y muerte la filosofía no tiene nada que justificar, su rol es de denuncia y de resistir cualquier intento del soberano (del Estado) de normalizar o dar razones para justificar sus decisiones, decisiones que por principio para ellas son injustificables. Lo primero que podríamos decir es que muchas concepciones filosóficas rechazarían esa visión tan estrecha de la filosofía. Nadie negará, como ya se dijo, que hay muchas otras cuestiones que son filosóficamente relevantes, incluso más relevantes, pero aquí el punto está en que ellas niegan la relevancia de la filosofía en cuestiones sobre decidir quién vive y quién muere. Me pregunto qué pensarán sobre si legalizar o no el aborto, la eutanasia, el problema de donación y asignación de órganos, el problema de legalización de drogas, entre otros, tienen o no relevancia filosófica. Supongo que también negarán que la tengan pues son cuestiones sobre la vida y la muerte.

En segundo lugar, se podría decir que no todo problema de elección en el triaje es, necesariamente, una cuestión de vida o muerte. Por un lado, la muerte es probable aún en caso de que un paciente sea admitido a una unidad de cuidados críticos (UCG) y, por otro lado, la muerte no es una consecuencia necesaria - aunque sí altamente probable - en caso de que no sea admitido. Rechazar a alguien de una UCC tampoco implica necesariamente 
Este libro forma parte del acervo de la Biblioteca Jurídica Virtual del Instituto de Investigaciones Jurídicas de la UNAM

que no pueda canalizársele a otro hospital o área donde pueda ser atendido o proporcionarle otro tipo de cuidados paliativos.

Tercero, su argumento supone también defender una tajante separación entre moral y política, donde la "decisión soberana" (si entiendo, la decisión del Estado o del gobierno de establecer criterios de triaje), nunca puede justificarse moralmente, de ahí que la filosofía no pueda decir nada.

Habrá que partir de que el escenario bajo el cual se trabajó en la Guía es real. La elección que tiene que hacerse sobre a quiénes ofrecerles atención en UCG no es un caso hipotético en el sentido de meramente imaginario (filosóficamente hablando, eso tampoco debería ser un problema). Este tipo de situaciones de escasez pueden tener grados de gravedad y duración, pero son bastante comunes en los servicios de salud aún sin pandemias. Esto no significa que no debamos preguntarnos por las causas del abandono de los servicios de salud pública; no significa que no debamos ocuparnos de las razones - falta de previsión, mala asignación de recursos económicos-, por las cuales llegamos a situaciones como la actual, pero ocuparse de esto no implica ignorar que la escasez es una situación inescapable, ${ }^{8}$ que tener un mejor servicio de salud pública no implica poder evitar esos escenarios de escasez relativa o de situaciones de emergencia.

Sostener que no se debe, que es inaceptable "normalizar una lógica" para decidir quien vive y quién muere, es simplemente un buen deseo que supone negar el problema o estipular un límite arbitrario para la razón, y no creo que eso sea lo mejor que la filosofía puede hacer. Hay elecciones difíciles y elecciones trágicas, en ambas alguien tiene que decidir y poder distinguir entre ambos casos supone indagar si podemos encontrar algún criterio para distinguir lo correcto, bueno, justo para decidir; incluso cuando esas preguntas se tornen en encontrar lo que sea menos incorrecto, malo o injusto.

Pensemos ahora, por ejemplo, en un principio ampliamente aceptado en el ámbito médico y retomado en la guía: el principio de necesidad. Este principio supone distinguir entre salud y atención a la salud (o servicio de salud). La idea es que cuando la atención de la salud no puede garantizar que la salud de una persona sea mejor de lo que hubiera sido sin dicha atención (sin negar que existe la necesidad de tener salud), difícilmente puede justificarse brindar atención médica pues esta resultaría inútil (fútil) y los recursos se derrocharían (asumiendo que son escasos). Se pueden ofrecer otros servicios (por ejemplo, cuidados paliativos), pero sabiendo que ellos tienen otro propósito, no el de curar. La forma como este principio de necesidad se traduce

8 Harris, John, "Deciding Between Patients", en Helga Kuhse y Peter Singer (eds.), A Companion to Bioethics, 2a. ed., Wiley-Blackwell, Singapore, 2009, pp. 335-361. 
Este libro forma parte del acervo de la Biblioteca Jurídica Virtual del Instituto de Investigaciones Jurídicas de la UNAM

en la práctica médica es algo complejo y supone adoptar posturas morales o éticas que impactarán en las decisiones. Supone adoptar alguna noción de necesidad y algún o algunos criterios (no filosóficos necesariamente) para determinarla o medirla. Y supone determinar qué criterios son relevantes para hablar de la necesidad de un tratamiento médico. Estos criterios nos permiten justificar, por ejemplo, que la pérdida de la vida, en principio, será más grave que alguna otra pérdida, como perder calidad de vida por ejemplo. ${ }^{9}$ Pero incluso determinar si es "en principio" o "siempre" que la pérdida de la vida es lo más grave, es una cuestión moralmente debatida. Y será igualmente debatido si quien pierde más es quien más años ha vivido, o al contrario si quien pierde más es quien tiene más años por vivir, o si gana más quien gana más años de vida de calidad, o si simplemente no hay nada que medir o calcular y todas las vidas valen igual y quienes ganan, ganan lo mismo y quienes pierden, pierden lo mismo. Podemos tener intuiciones fuertes sobre estas cosas, pero nada hay obvio en todo esto, son cuestiones que en la filosofía y, particularmente en la bioética, se han discutido desde hace tiempo y se seguirán discutiendo.

Volviendo al argumento de González y Martínez — si no hay asunto filosófico (ético), que debatir en estos casos, es porque no hay ninguna decisión justificable en estos casos-, éste presenta una ambigüedad cuando sostienen que cualquier decisión sería "injustificable". Por un lado, podría querer decir que no hay argumentos para justificar o condenar la decisión, por eso está fuera del campo de la ética. Por otro lado, parece que dicen que cualquier decisión es injustificable porque es incorrecta, reprobable, injusta. En este segundo caso parecería se contradicen: si "por principio" es incorrecta e injustificable, entonces suponen que existe un principio moral y con él se fundamenta que toda decisión de ese tipo es incorrecta. La cuestión que surge entonces es cuál es ese principio y cómo lo fundamentan ellas, pero entonces sí que sería una cuestión filosófica. Les queda entonces sostener que tales decisiones no pueden ni justificarse ni condenarse, serían entonces o inocuas o trágicas, pero como seguramente no pensarán que son inocuas deben considerarlas trágicas.

La tesis de que hay conflictos trágicos que son irresolubles, es una tesis filosófica (o epistémica) sobre los límites de la razón. ${ }^{10}$ Pero también hay quienes consideran que las elecciones trágicas (o dilemas morales genuinos)

\footnotetext{
$9 \quad$ Ibidem, p. 337.

10 La tesis ha sido sostenida, por ejemplo, por Jon Elster, fuicios salomónicos. Las limitaciones de la racionalidad como principio de decisión, Barcelona, Gedisa, 1995; y por Terrance McConnell, "Moral Dilemas", Stanford Encyclopedia of Philosophy, 2010.
} 
Este libro forma parte del acervo de la Biblioteca Jurídica Virtual del Instituto de Investigaciones Jurídicas de la UNAM

pueden resolverse, aunque siempre queda un resabio moral porque el costo es muy alto. Junto a autores que sostienen este tipo de tesis, están también quienes han rechazado que existan dilemas genuinos o casos trágicos (irresolubles). No es mi propósito ahora sostener cuál de las tesis es mejor filosófica o epistémicamente hablando, lo que creo es que los casos de triaje, por lo general, son casos dificiles pero no casos trágicos (irresolubles), ${ }^{11}$ precisamente porque podemos tener criterios justificados para decidir.

Subsiste todavía otro problema para la tesis que estamos discutiendo: si el problema es moralmente irresoluble, cómo debe decidirse, suponiendo que de cualquier manera alguien tiene que decidirlo y suponemos (sin aceptar) que no puede resolverse moralmente. Decir que debe decidirse con criterios médicos no es errado, pero si este argumento se utilizara supondría que no hay conexión alguna entre los criterios médicos y los éticos, cosa que ya nos lleva a otro problema semejante al de si la política está (debe estar) desconectada totalmente de la moral. Otra forma de decidir sería de modo aleatorio, por azar, pero ello también requerirá alguna justificación, como veremos más adelante. Por donde vaya su argumento parece que irremediablemente se topará con alguna discusión filosófica.

\section{La negación del dilema ético entre salvar vidas (o proteger derechos) en situaciones de escasez de recursos}

La Comisión Nacional de Derechos Humanos afirmó en un comunicado de prensa que no había dilema, que todas las personas deben ser atendidas. Aunque no se elaboró un argumento propiamente filosófico, creo que esta afirmación es típicamente una afirmación (confusión) filosófico-conceptual que suele presentarse a menudo en discusiones sobre los derechos humanos.

...a GNDH llama la atención para que se tomen en cuenta cuestiones tales como la de saber si desde la perspectiva del bloque de constitucional (sic), la eventual aplicación de esta Guía violaría los derechos humanos de quienes no recibieran atención urgente debido a las circunstancias extremas de no disponer de recursos suficientes.

A partir del análisis desde el bloque constitucional de derechos humanos, es importante precisar que la Guía es contraria a disposiciones sobre el derecho a la salud vinculantes para México, tanto en el Sistema Universal como

11 Sobre los casos trágicos puede verse Lariguet, Guillermo, "Conflictos trágicos genuinos, ponderación y límites de la racionalidad jurídica. En torno a algunas ideas de Manuel Atienza", en Isonomía, núm. 24, 2006, abril, pp. 93-114. 
Este libro forma parte del acervo de la Biblioteca Jurídica Virtual del Instituto de Investigaciones Jurídicas de la UNAM

en el Sistema Regional de protección de los derechos humanos, ya que es un documento que justifica que el Estado Mexicano no garantice el acceso efectivo a los bienes de salud a todos los pacientes con COVID-19, en este caso a los recursos de medicina crítica.

Los ciudadanos deben saber que, en estas circunstancias excepcionales, sus derechos más fundamentales continúan igualmente garantizados, porque las libertades y los derechos no se suspenden por muy difícil que sea el reto.

Los derechos humanos no deben ser objeto de ningún dilema. ${ }^{12}$

La afirmación de la CNDH supone ignorar que existen dos dimensiones: la normatividad y la facticidad (realidad), pues asume que lo normativo es $y$, por ende, termina negando que la realidad sea distinta; un viejo error no poco frecuente entre abogados, que se conoce como la falacia normativista.

Otra manera en que se presentó el argumento, ahora por parte de un ex presidente de la GNDH, Luis Raúl González Pérez, fue sosteniendo que las obligaciones en materia de derechos humanos harían inconstitucional pensar en un escenario como el que se plantea la Guía (de escasez de recursos de medicina crítica), dado que la obligación del Estado es prevenir que ello no ocurra y garantizar atención a todas las personas; así lo expresaba el ex ombudsperson:

Estas obligaciones constitucionales, que también se encuentran contenidas en diversos instrumentos internacionales suscritos por el Estado mexicano, no dejan espacio a dudas respecto a que la conducta debida por parte de los servidores públicos, en todo momento, es el cumplimiento de la ley, de las obligaciones que la misma les impone, lo cual lleva implícito el respeto y garantía de los derechos humanos de todas las personas. ${ }^{13}$

Es cierto que las obligaciones de promover, respetar, proteger y garantizar los derechos humanos obligan a todos los servidores públicos y a los órganos del Estado. Sin embargo, pasar de esta afirmación a negar la posibilidad de que entre derechos haya posibilidad de contradicciones o dilemas es una cuestión teórico-conceptual, también una cuestión ideológica. El iusnaturalismo del siglo XVII y más tarde el liberalismo del siglo XIX ofrecieron una visión romántica e idealizada de los derechos del hombre y

12 Comunicado de Prensa DGC/137/2020, del 17 de abril de 2020. Puede consultarse en: https://wrerr.cndh.org.mx/sites/default/files/documentos/2020-04/com_2020_137_0.pdf.

13 González Pérez, Luis Raúl, "Ética y COVID-19", Animal Político, 22 de abril de 2020, disponible en: https://wrereanimalpolitico.com/una-vida-examinada-reflexiones-bioeticas/etica-y-covid-19/. 
Este libro forma parte del acervo de la Biblioteca Jurídica Virtual del Instituto de Investigaciones Jurídicas de la UNAM

del ciudadano. Se pensaba que el único límite para ejercer los derechos era el no dañar a terceros, de modo que cada derecho tenía su propio límite y así todas las libertades podían armonizarse. Pero esto no era otra cosa que un buen deseo que se materializó en una ideología (liberal) que ocultaba el hecho de que el ámbito de las libertades (civiles y políticas), como lo viera Hohfeld $^{14}$ desde principios del siglo XX, conlleva muchas veces confrontación y daño a otros, daño que en una sociedad capitalista está implícito en la idea de libertad económica y de empresa, pero que igualmente se encuentra presente en muchos otros ámbitos donde hay competencia. Ejercer libertades implica en ocasiones imponer los intereses de uno sobre los de otro, competir por un bien (un puesto laboral, un lugar en la universidad, una obra pública, una competencia deportiva, un premio artístico, etc.), implica que sólo alguno(s) puede(n) ganar, los demás pierden al no obtener el bien en cuestión y pueden perder lo que hayan invertido para conseguirlo (esfuerzo, tiempo, dinero, etc.). Que uno tenga derecho a la educación, a la salud y otros tantos bienes, no quiere decir que éstos puedan producirse o estén siempre disponibles para todos. El que exista un deber de garantizarlos es importante, pero los estados de cosas no se producen con sólo legislar al respecto; el paso de lo normativo a la fáctico no es automático, supone llevar a cabo acciones que no siempre consiguen sus objetivos. Ante situaciones donde no se ha logrado la garantía efectiva, el querer hacer una atribución de responsabilidad supone no sólo que el deber sea formalmente exigible (por ser parte de obligaciones genéricas), sino que ante la situación específica se pueda imputar tal responsabilidad porque no haya excusas válidas que oponer. En un sentido muy básico el deber implica poder. Si no es posible fáctica o humanamente hacer algo, entonces no se puede imputar responsabilidad. Hay otros criterios también para imputar responsabilidad, pero ahora no puedo detenerme en ese tema.

También importa distinguir el tipo de acción que se exige. Las normas ordenan muchas veces acciones complejas o alcanzar estados de cosas (normas de fin) que implican una evaluación sobre el conjunto de acciones que podrían realizarse para tratar de alcanzar el objetivo, sin que haya muchas veces una relación de causalidad necesaria entre tales acciones y el logro del estado de cosas. En el caso que nos ocupa, el Estado está obligado a ofrecer atención de cuidados críticos en la pandemia de COVID-19. Para ello, el gobierno federal puede, entre otras acciones, comprar respiradores; pero

14 Hohfeld, W. N., Conceptos jurídicos fundamentales, Fontamara, México, 1991. Véase también mi análisis de la obra de este autor, particularmente de su noción de libertad en Cruz Parcero, Juan Antonio, El concepto de derecho subjetivo, México, Fontamara, 2a. ed., 2017. 
Este libro forma parte del acervo de la Biblioteca Jurídica Virtual del Instituto de Investigaciones Jurídicas de la UNAM

aun cuando se realice esta acción el objetivo puede no alcanzarse si no hay suficientes respiradores en el mercado, si no se logran producir a tiempo, si los que se compran no sirven de manera adecuada, o si los precios del mercado son tan altos que no se pueden adquirir en cantidad suficiente. La atribución de responsabilidad no puede pasar por alto que puede haber excusas justificables por las cuales no se logre cumplir con una obligación. Los casos claros de responsabilidad ocurren cuando los gobiernos no hacen nada, pero cuando los gobiernos hacen algo, pero no logran los resultados esperados, la evaluación sobre la imputación de responsabilidad se torna más compleja. Nada de lo dicho implica que no se pueda atribuir responsabilidad, se advierte solamente que no es suficiente no haber obtenido el resultado esperado. Esto ocurre así con muchos deberes asociados con derechos sociales, como el derecho a la salud. ${ }^{15}$

Los médicos y el personal de salud, en casos de emergencias sanitarias, donde un escenario de escasez de recursos es algo inevitable (al menos relativamente), no pueden estar obligados a brindar atención a la salud a todo el que la necesita. Humanamente no podrían ellos mismos multiplicarse, y tampoco podrían obtener los recursos que por razones ajenas a ellos no se lograron producir o adquirir con tiempo. El Estado mismo, su gobierno, puede estar en circunstancias semejantes: si por años gobiernos anteriores no invirtieron en salud, no se previeron escenarios catastróficos como una pandemia o habiéndolos previsto no destinaron los recursos suficientes, sería injusto responsabilizar - por ejemplo, a un nuevo gobierno - por algo que hicieron gobiernos anteriores, al menos responsabilizar a los funcionarios de ese gobierno como causantes del problema. Otra cuestión sería si el gobierno o el Estado deben responder o asumir una responsabilidad política o jurídica de forma vicaria (por otras consideraciones que pueden valer en esos ámbitos, aunque no exista la responsabilidad moral o causal).

Las ideas de la integralidad e interrelación de los derechos humanos, ideas aceptadas en la Conferencia Mundial sobre Derechos Humanos de Viena (1993), supone que la protección de los derechos debe hacerse de manera que abarque a todos los derechos sin desconocer a algunos derechos o negarles su estatus de derechos humanos (cosa que se solía hacer con los derechos sociales), e implica que la vulneración de uno puede tener repercusiones en otros. Pero esta misma idea de la interrelación supone aceptar que cuando desde el Estado, por ejemplo, se canalizan recursos para la educación (y con ello para otros derechos relacionados), a su vez es posible que

15 Véase el capítulo 3 "Derechos sociales: clasificaciones, normas, acciones y fines", en Cruz Parcero, Juan Antonio, El lenguaje de los derechos, Madrid, Trotta, 2007. 
Este libro forma parte del acervo de la Biblioteca Jurídica Virtual del Instituto de Investigaciones Jurídicas de la UNAM

otros derechos queden menos protegidos. Si proteger derechos conlleva destinar recursos financieros y humanos a su protección, y si partimos de que esos recursos son normalmente escasos (relativamente escasos), programar el gasto público incide en qué derecho se verán más o menos protegidos (desde luego la protección y garantía de los derechos no depende solamente de los recursos que se destinen, también de que se haga un buen uso de ellos, haya una planificación adecuada, no haya corrupción y de otras tantas variables). Determinar cuánto dinero se destinará a la salud, cuánto a la educación, a la vivienda, a la seguridad pública, a la promoción del empleo, al desarrollo de la economía, a los pobres y otros grupos vulnerables como los adultos mayores o los niños, a la alimentación, etc., supone elecciones difíciles que son más delicadas en tanto menos recursos se tengan o más carencias o urgencias se tengan.

El criterio de progresividad de los derechos humanos supone por ello que las obligaciones para ser exigibles deben ser razonablemente determinadas en las circunstancias y condiciones donde los derechos humanos han de realizarse; de otro modo caeríamos en el absurdo de que el gobierno de países como Noruega, Japón o Alemania tienen las mismas obligaciones concretas que gobiernos como El Salvador, Haití o Costa de Marfil. Y aunque todos tienen las mismas obligaciones generales de proteger, garantizar, promover y desarrollar los derechos humanos, en cada circunstancia y contexto esas obligaciones se determinan o especifican de diverso modo y, en este sentido, la responsabilidad de los obligados también dependerá de ese tipo de circunstancias y contextos.

De modo que sostener que no hay dilemas, tensiones o contradicciones entre los derechos, o sostener que las obligaciones derivadas de los derechos humanos son incondicionales, supone trabajar con una mala teoría de los derechos o una concepción ideologizada de los mismos, y supone una mala teoría de la responsabilidad tanto moral, jurídica y política.

\section{El problema de los criterios utilitaristas}

El Observatorio Filosófico de México publicó un posicionamiento en contra de la Guía que suscribieron varios filósofos y filósofas; en su segundo punto se dice:

Las decisiones sobre la vida y la muerte de los ciudadanos no pueden ser basadas en criterios extraídos de la concepción utilitarista (citada expresamente en el documento, ya que se alude a Jeremy Bentham de una manera distorsio- 
Este libro forma parte del acervo de la Biblioteca Jurídica Virtual del Instituto de Investigaciones Jurídicas de la UNAM

nada pues sus planteamientos distan de lo que propone la guía [sic]), puesto que convierten a la persona en un objeto; recomienda una toma de decisiones basadas en la "utilidad" o "inutilidad" y violentan la dignidad de las personas, que es un principio esencial defendido por la bioética. ${ }^{16}$

Aunque la acusación es confusa (dado que se dice que los planteamientos de Bentham distan de lo que se propone en la Guía), ${ }^{17}$ trataré de interpretar la acusación de usar criterios utilitaristas de modo serio. Además, no fue la única vez que se hizo esta acusación, uno de los firmantes de la carta, Guillermo Hurtado - un destacado filósofo del Instituto al que pertenezco-, sostuvo que el principio de salvar la mayor cantidad de vidas posible:

...está fundado en la filosofía llamada utilitarismo. De acuerdo con esta doctrina, un acto bueno es aquel que tiene como consecuencia la mayor cantidad de beneficios para el mayor número de personas. El utilitarismo es una doctrina ética fundada en una regla cuantitativa. De aquí se desprende, por ejemplo, que es moralmente mejor salvar las vidas de cien personas que salvar las de noventa y nueve. Esta regla de acción vale en todos los casos. No importa que para salvar a esas cien personas se tenga que dejar morir o incluso sacrificar a unos cuantos (sic).

La Guía bioética toma esta regla como principio básico. De aquí se desprende que durante el pico de la pandemia los servicios de salud tendrán que usar sus recursos limitados para concentrarse en salvar a quienes tengan más probabilidades de sobrevivir, por encima de quienes tienen menos probabilidades. Instalar un respirador artificial a alguien que quizá sólo vivirá un par de horas es moralmente incorrecto, desde la perspectiva utilitarista, si hay otra persona que necesita el respirador y quizá se recupere en dos días. Aunque el primer paciente, el más grave, haya llegado primero al hospital, el respirador se le asignará al segundo, el menos grave, por más que éste haya llegado después. El objetivo final, recordemos, es salvar el mayor número de vidas, cueste lo que cueste. Sin compasión alguna.

Insisto, no pregunto si es la medida más eficiente. No, lo que pregunto es si es la más moral, ¿la que se ajusta mejor a nuestro concepto del bien?

\footnotetext{
16 Se puede consultar en: http://wrere.ofmx.com.mx/inicio/wp-content/uploads/2020/04/ Declaración-OFM-Guía-Bioética.pdf.

17 Como he dicho antes, se pudo haber tratado de hacer otra interpretación, pero la actitud asumida era de denuncia o de confrontación, es claro que no se buscó una mejor interpretación, cosa que cualquier filósofo de los firmantes pudo haber intentado de haber asumido otra actitud.
} 
Este libro forma parte del acervo de la Biblioteca Jurídica Virtual del Instituto de Investigaciones Jurídicas de la UNAM

Quienes defienden la Guía sostienen que es mejor tener un criterio que no tener ninguno. No estoy de acuerdo. Es mejor no tener un criterio que tener uno inhumano. ${ }^{18}$

En su texto no nos dice cuál sería el principio correcto, aunque supone que su argumento logra mostrar la inhumanidad de los principios utilitaristas que se utilizan en la Guía. Sugiere, sin decirlo de manera explícita, que sería injusto dejar de lado el principio de orden de llegada, que sería mejor, más humano, atender a quien va a morir en un par de horas que priorizar a quien se puede salvar. Curioso que sea esta conclusión la que implícitamente considera moralmente correcta, la más humana. Ya hablé en II.1. del principio de necesidad y parece que esta sugerencia hace a un lado este principio, parece entonces que la atención médica tiene algo así como un valor intrínseco y que no importa a quién se atienda ni qué resultados u objetivos busque la atención médica. Quizá la confusión de Hurtado se podría salvar diferenciando entre atención médica y otro tipo de atención, como son los cuidados paliativos, distinción que se encuentra en la Guía.

Ahora bien, decir que el principio de salvar el mayor número de vidas sea un principio que tenga que aplicarse "sin compasión", "cueste lo que cueste", frente a quienes no son beneficiados de la atención de cuidado críticos, no es algo que se desprende del principio. Nada impide que un principio como este se aplique con compasión. La afirmación supone algo así como la mala fe y la maldad de los utilitaristas y, en concreto, de quienes usen este principio de salvar el mayor número de vidas posible. Sencillamente creo que la conclusión que sugiere Hurtado no se sigue. En el proyecto de Guía (y en la versión final) se contemplaba continuar con atención hospitalaria, atención psicológica y de cuidados paliativos para quienes no fueran elegidos.

Es verdad que el utilitarismo tiene mala reputación entre muchos filósofos. El utilitarismo, según James Rachels, puede resumirse en tres proposiciones: a) las acciones se juzgan como correctas o incorrectas solamente

18 Hurtado, Guillermo, "Salvar el mayor número de vidas cueste lo que cueste", La Razón, 21 de abril del 2020. Consultable en: https://wwrw.razon.com.mx/opinion/guillermo-hurtadosalvar-el-mayor-numero-de-vidas-cueste-lo-que-cueste/. Véase también otros dos textos sobre la guía de este filósofo: "Hay vidas que valen más que otras", La Razón, 25 de abril de 2020. Consultable en: https://wrwrerazon.com.mx/opinion/guillermo-hurtado-hay-vidas-que-valen-mas-que-otras/, y "Dilemas fatales y decisiones éticas", La Razón, 28 de abril de 2020. Consultable en: https:// wrere.razon.com.mx/opinion/guillermo-hurtado-dilemas-fatales-y-soluciones-eticas/. Argumentos muy parecidos uso también Gabriel Vargas Lozano en "Ética del comité de bioética", La fornada, 18 abril 2020, consultable en: https://wrere.jornada.com.mx/2020/04/18/opinion/006a1pol\#. xptcpk1mr40.twitter. 
Este libro forma parte del acervo de la Biblioteca Jurídica Virtual del Instituto de Investigaciones Jurídicas de la UNAM

en virtud de sus consecuencias (consecuencialismo), $b$ ) al evaluar las consecuencias lo único que importa es la cantidad de felicidad o infelicidad que se crea (maximización y hedonismo), c) la felicidad de cada uno cuenta por igual. ${ }^{19}$

El hedonismo que se defendió por el utilitarismo clásico (Bentham y Mill), podemos dejarlo de lado en esta discusión, dado que ha sido ampliamente desacreditado y los mismos utilitaristas contemporáneos lo suelen rechazar. Además, es algo que no tiene nada que ver con el proyecto de Guía, pues en éste se alude a tres principios sospechosamente utilitaristas: salvar la mayor cantidad de vidas posible, igual valor de las personas y, como una excepción, priorizar al personal médico. El primero de estos principios implica mirar a los resultados (consecuencias): tratar de maximizar el salvar vidas, pues se asume que la vida es un valor fundamental. El segundo principio asume que las vidas humanas tienen igual valor, que no debe haber discriminación ni exclusión de nadie. El tercero, asume como una necesidad instrumental para garantizar los servicios de salud, priorizar la atención y acceso a las UCC al personal de salud que está en primera línea en la lucha contra la pandemia.

$\mathrm{Al}$ utilitarismo se le ha reprochado, con acierto, que la utilidad (la maximización de un bien) no es lo único que importa para determinar si una acción es correcta o no lo es. Pero hay que recordar que el utilitarismo surgió históricamente como una reacción a una concepción opuesta, donde la corrección de una acción se evaluaba de conformidad con alguna regla o principio moral, sin mirar a las consecuencias que pudiera producir (en una época donde además esas reglas eran principalmente las de una moral cristiana), de esta forma la idea sería que hay ciertas cosas que no se deben hacer (o que están ordenadas) sin importar qué consecuencias tengan. Así vistas estas dos posturas, el deontologismo y el utilitarismo (o consecuencialismo), parecen posturas opuestas con graves problemas cada una y muy exigentes para quienes las suscriban en la práctica.

Pienso que hoy día la mayoría de las posturas morales saben que hay varias cuestiones que son importantes para la moral, que nos deben importar los principios, los valores, los derechos, los deberes, las virtudes, pero también las consecuencias (y los números, como suele decirse). Desde el mismo deontologismo y el mismo utilitarsimo (por ejemplo, el llamado utilitarismo de regla, aunque por diversas razones - que aquí no analizaremos - no resultó del todo atractivo), se ha tratado de dar cabida a esta pluralidad de criterios importantes, de buscar vías intermedias.

19 Rachels, James, Introducción a la filosofia moral, México, FCE, 2013, p. 167. 
Este libro forma parte del acervo de la Biblioteca Jurídica Virtual del Instituto de Investigaciones Jurídicas de la UNAM

Una de estas corrientes intermedias se define como no consecuencialista. La idea del no-consecuencialismo es que la corrección o la incorrección de una conducta no está determinada solamente por la bondad o maldad de las consecuencias de nuestros actos o de las reglas a las que nuestros actos se conforman..$^{20}$ Los no-consecuencialistas se toman en serio la segunda formulación del Imperativo categórico de Kant que ordena siempre tratar la humanidad de uno y de los demás como fin en sí mismo y nunca sólo como un medio. De aquí derivamos el deber de tratar a las personas como fines por sí mismas y la prohibición de tratarlas solamente como medios. ${ }^{21}$ David Ross ${ }^{22}$ quien ha inspirado a muchos filósofos (y a muchos juristas) contemporáneos, sostuvo la idea de que hay muchos deberes prima facie (de no dañar, de beneficiar, de gratitud, de justicia, incluido el deber de maximizar el bienestar), que estos deberes suelen entrar en conflicto y que no hay una sola escala para determinar cuál de ellos deba prevalecer. Que los deberes puedan ser inconmesurables no significa que no podamos tomar decisiones correctas en casos de conflictos. ${ }^{23}$

Lo importante aquí para mi argumento es que el no consecuencialismo no rechaza que las consecuencias (la maximización, los números) cuenten moralmente. Sería, si no absurdo, al menos muy extraño que no contaran. Este tipo de postura ha puesto algunos ejemplos paradigmáticos, uno de ellos es el famoso caso del tranvía: ${ }^{24}$ un tranvía baja por la vía sin freno y de no desviarse matará a cinco personas, un guardavía que lo ve venir puede desviarlo hacia otra vía donde mataría a una persona. En este caso el utilitarismo diría que la única solución correcta sería desviarlo para salvar a cinco, aunque muera una persona; el deontologismo diría que el guardavía no debe hacerlo porque ello equivaldría a matar. ${ }^{25}$ La mayoría de los no consecuencialistas (y de quienes buscan una posición intermedia) estarían de acuerdo que en este tipo de casos salvar a cinco es la conducta correcta, aunque si las circunstancias fueran distintas, podrían considerar que salvar a cinco a

20 Kamm, F. M., Intricate Ethics. Rights, Responsibilities, and Permissible Harm, Oxford University Press, EUA, 2007, p. 11.

21 Ibidem, p. 13.

22 Ross, David W., The Right and the Good, Oxford University Press, Oxford, 1930.

23 Por cierto - y a propósito de lo que discutíamos en el apartado II.1-, Ross niega que haya dilemas morales genuinos, pues en una situación concreta siempre habrá un deber o un valor que tenga más peso.

24 Para una extensa e interesante discusión sobre este caso véase Kamm, F. M., The Trolley Problem Misteries, Oxford University Press, EUA, 2015.

25 Aquí asumo que defensores de esta posición suelen distinguir entre obligaciones negativas y positivas, siendo las negativas obligaciones perfectas, con mayor peso que las obligaciones de hacer o imperfectas. 
Este libro forma parte del acervo de la Biblioteca Jurídica Virtual del Instituto de Investigaciones Jurídicas de la UNAM

costa de uno no siempre es lo correcto, por ejemplo, si fuese la hija del guardavía la involucrada, éste no tendría por qué preferir a los otros cinco, pues se puede admitir que las relaciones especiales de las personas cuentan moralmente y que no le sería moralmente exigible al guardavías sacrificar a su hija. Otros tantos casos podrían hacer que salvar a cinco no fuese la opción correcta, pero se trataría, precisamente, de circunstancias especiales. Si todas las consideraciones permanecen igual, la importancia moral de los números en cuestiones que atañen a las políticas públicas parece difícil de ponerse en duda. Pero habrá que ser cautos cuando afirmamos que los números cuentan moralmente. En realidad, cuando decimos esto estamos afirmando que las vidas humanas tienen valor y que una persona más que es salvada añade valor a nuestra acción, de modo que el principio de salvar el mayor número de vidas posible se justifica en parte no sólo por los números sino, porque las vidas las consideramos moralmente valiosas y fallaríamos en considerarlas igualmente valiosas si no se aceptara tal principio. ${ }^{26}$

La pregunta, volviendo a la Guía bioética, es si estamos adoptando una concepción utilitarista ("cueste lo que cueste"), o una concepción más parecida al no-consecuencialismo. Si revisamos el proyecto de Guía ${ }^{27}$ podemos encontrar lo siguiente:

a) Se aplicará exclusivamente para casos especiales donde la capacidad de las unidades de cuidados críticos está sobrepasada;

b) Se asume el principio de necesidad médica;

c) Se rechaza el principio de orden de llegada por ser discriminatorio;

d) Se reconocen que en la práctica médica en situaciones ordinarias operan los principios de beneficencia, no maleficencia, autonomía y justicia;

e) Se asume que en la salud pública el principio que gobierna es el de justicia social, y que en una situación de pandemia rige principalmente este principio;

26 El argumento es de Scanlon, Thomas S., What We Owe to Each Other, Harvard University Pres, Cambridge Mass., 1998, p. 232. Aunque dije que es difícil de poner en duda la afirmación de la relevancia moral de los números es algo que se ha hecho por algunos filósofos, entre los más destacados Anscombe, G. E. M., "Who is Wronged?", The Oxford Review, núm. 5, 1967, pp. 16 y 17. Anscombe trata de refutar un ejemplo de Philippa Foot en favor de la doctrina del doble efecto, en "The Problem of Abortion and the Doctrine of Double Effect", en esa misma revista, pp. 5-15.

27 En la versión final aprobada, se eliminó el criterio de salvar la mayor cantidad de vidas por completarse y se incorporó en su lugar (casos de empate) priorizar a personas que pertenezcan a grupos vulnerables y en última instancia se mantiene decidir aleatoriamente. 
Este libro forma parte del acervo de la Biblioteca Jurídica Virtual del Instituto de Investigaciones Jurídicas de la UNAM

f) Se asume como principio de justicia social que todas las personas tienen un mismo valor, que se traduce en el principio de no exclusión y se reconoce un igual derecho a recibir atención médica;

g) Se sostiene que características como la edad, sexo, afiliación política, discapacidad y riqueza no excluyen a ningún paciente de ser candidato para recibir atención médica;

h) El objetivo de la salud pública en una pandemia es tratar el mayor número de pacientes y salvar la mayor cantidad de vidas, $\mathrm{y}$

i) Finalmente, en casos donde los pacientes presenten circunstancias equivalentes (empates), se propone usar el criterio de salvar la mayor cantidad de vidas por completarse, y de no poderse usar éste se recurre en última instancia al azar.

Si contemplamos todos estos criterios, resulta muy difícil entender que detrás de ellos exista una concepción utilitarista que se aplique "cueste lo que cueste". Es verdad que en el proyecto de Guía se citaba a Bentham en apoyo de la idea de que todas las personas poseen igual valor ("cada uno cuenta por uno, nadie por más de uno"). Pero ¿justifica la alusión al padre del utilitarismo que se dejen de ver principios de no exclusión y discriminación, que se parte del reconocimiento de la titularidad de derechos humanos en condiciones de igualdad y, particularmente, del derecho de acceso a la atención de la salud? Reconozco que quizá fue un error de comunicación citar a Bentham, era innecesario, pero creo que la interpretación utilitarista de la Guía es una distorsión propia de algunos filósofos para quienes solo existen dos alternativas, ser utilitarista (consecuencialista) o ser deontologista (algunos se dicen humanistas). Particularmente yo no me considero utilitarista, pero no dejaría de reconocer la pertinencia de ser sensibles a las consecuencias y de adoptar en algunas circunstancias, como la de una pandemia, algún o algunos criterios utilitaristas, que quedan a mi modo de ver justificados por su relevancia en este tipo de situaciones y por que son compatibles con otras consideraciones morales que consideramos importantes (derechos, deberes, principios).

\section{4. ¿Hay vidas más valiosas que deban preferirse en el triaje?}

¿Podríamos sustituir el principio de salvar la mayor cantidad de vidas posible por algún otro? Tratar a los pacientes en orden de llegada sin considerar la necesidad o la probabilidad de que puedan salvarse sería francamente una pésima política de salud, una muy irresponsable, que 
Este libro forma parte del acervo de la Biblioteca Jurídica Virtual del Instituto de Investigaciones Jurídicas de la UNAM

ocasionaría más muertes e injusticias. ¿Se podrían usar otros criterios como el mérito o demérito, valor social, las relaciones personales, los intereses de terceros, el interés manifiesto de los pacientes?

En el debate público se hicieron ese tipo de propuestas, muchas veces acompañadas con descalificaciones racistas, clasistas o de otra índole. Pero también algunos filósofos presentaron argumentos y dudas más serias. Héctor $\mathrm{Zagal}^{28}$ por ejemplo, se preguntaba si habría que darle prioridad a un joven frente a un funcionario adulto mayor de alto rango, o frente a un adulto que mantiene una familia, o frente a un delincuente. En sus preguntas, me parece, estaba implícita la sugerencia de que criterios como el valor social (rango), la responsabilidad de la persona, o las relaciones con terceros podrían ser un criterio relevante en el triaje. Zagal no justifica sus sugerencias, apela simplemente a nuestras intuiciones, o mejor dicho, a algunas intuiciones, pues como veremos apelando a nuestras intuiciones también podríamos ver por qué tales criterios alternativos son irrelevantes en esta situación.

No niego que criterios como el mérito o el valor social suelen ser relevantes moral y socialmente, sin embargo, la cuestión es si siempre son relevantes, o si en el caso específico que contempla la Guía deben ser tomados en cuenta. Estos criterios suelen usarse en distintos ámbitos sociales, pero rara vez exigimos se usen en todos. El que vengan aconsejados en cierta situación, no implica que siempre lo sean, o que sean dejados de lado en alguna situación no implica recomendar su desconocimiento en otras situaciones. Es poco práctico pensar que un equipo de triaje médico de una UCG en una situación de pandemia donde las decisiones deben ser tomadas lo más rápido posible, podría tener la información relevante para poder evaluar quien tiene más méritos académicos, profesionales, económicos, políticos, artísticos o de alguna otra dimensión personal o social. Pedir que los pacientes lleguen, por ejemplo, al hospital con su currículum o con sus constancias de pago de impuestos, o con testigos para dar fe de su conducta responsable (algunos parecían sugerían esto), es verdaderamente un desatino. Conformar comisiones de triaje con expertos en otras tantas disciplinas para evaluar tales criterios también es irrazonable. A pesar de que en ciertas circunstancias sea razonable evaluar a las personas por algún tipo de mérito o valor social, incluso aceptando que en el ámbito médico esos criterios puedan ser relevantes en algunas ocasiones, no parece ser claro que en las condiciones de una pandemia, en una situación de triaje para acceder a una UCC, sean relevantes tales criterios. Aceptarlos en una guía supondría po-

28 Zagal, Héctor, “QQue se mueran los débiles!”, 24 horas, 21 de abril de 2020, consultable en: https://wrwr.24-horas.mx/2020/04/21/que-se-mueran-los-debiles/. 
Este libro forma parte del acervo de la Biblioteca Jurídica Virtual del Instituto de Investigaciones Jurídicas de la UNAM

ner de lado el principio de salvar el mayor número de vidas posible y optar por un principio elitista de salvar el mayor número de personas valiosas o con más méritos, principio que iría en contra de la igual dignidad y valor de las personas.

De por sí, como ha sostenido Arnoldo Kraus en algunas de sus intervenciones en medios, en México vivimos los efectos de dos pandemias, la de COVID-19 y la de la pobreza; la pobreza ya de por sí es una especie de triaje que selecciona a los más ricos para sobrevivir. ${ }^{29}$ Reafirmar el igual valor, igual dignidad e iguales derechos de las personas supone oponerse a esa realidad que discrimina y excluye en los hechos, y que ha sido parte de los problemas que tenemos en nuestro sistema de salud.

\section{5. ¿Priorizar en el triaje implica violar derechos o perpetrar un homicidio?}

Argumentos como los analizados, vertidos por la CNDH y otros participantes en el debate, apuntaban a que el triaje implicaría, de llevarse a cabo, la violación de derechos humanos e incluso que los médicos podrían incurrir en la comisión de un homicidio.

Nada más falso que esto, pero veamos por qué. Se suele atribuir a Tomás de Aquino la formulación del principio del doble efecto para justificar matar a otro en legítima defensa (mientras sea proporcional la respuesta). La idea básica sería que una acción es lícita o moral si persigue un fin valioso, aunque de ella se desprenda o pronostique un resultado malo (doble efecto). ${ }^{30} \mathrm{~A}$ lo largo de siglos los filósofos y juristas han discutido y refinado las condiciones para que sea legítimo invocar la doctrina del doble efecto. Ya vimos en II.3. el ejemplo paradigmático del tranvía, según el principio del doble efecto, la acción de desviar el curso del tranvía, aunque sea una acción voluntaria que anticipa una muerte, no puede considerarse moralmente incorrecta, ni ilícita (un homicidio), dado que su propósito es legítimo: pretende salvar a cinco vidas.

El principio del doble efecto ayuda a legitimar una acción que causa daño, siempre que el daño previsto, no querido, sea proporcional. La discusión sobre el principio del doble efecto ha sido filosóficamente intensa y así

29 Puede verse su comentario en una nota de El Universal, disponible en: https://wrere. eluniversal.com. $m x /$ nacion/coronavirus-util-considerar-voluntad-anticipada-en-contingencia-por-covid19-kraus.

30 Para mayores detalles, véase McIntyre, Alison, "Doctrine of Double Effect", The Stanford Encyclopedia of Philosophy, 2018, consultable en: https://plato.stanford.edu/entries/doubleeffect/. 
Este libro forma parte del acervo de la Biblioteca Jurídica Virtual del Instituto de Investigaciones Jurídicas de la UNAM

como hay defensores de este principio, hay también quienes han planteado dudas sobre el alcance y condiciones bajo los que debería operar el principio. Esta cuestión no la puedo abordar aquí pues sobrepasa los propósitos del trabajo. Me quedo con el señalamiento de que quienes equiparan el triaje con un homicidio, tendrían muchos problemas para justificar otras conductas que se consideran lícitas o moralmente correctas, como la legítima defensa o prácticas médicas cotidianas que suponen tomar riesgos, incluso de muerte, al medicar o al realizar intervenciones quirúrgicas.

Por lo demás, ya hemos dicho que suponer que hay una violación de derechos humanos en caso de que alguien no sea priorizado en el triaje, supone asumir una mala teoría de los derechos, además de ignorar el principio del doble efecto.

\section{La afirmación que en la Guía se discrimina a los adultos mayores}

Hay dos formas en que podemos entender la idea de discriminar: una que implica solamente la idea de distinguir o separar, y otra normativa, que implica que estamos frente a una distinción o trato injustificado o arbitrario. Discriminar a los adultos mayores en el segundo sentido supone ya la ilegitimidad del acto, en el primer sentido no.

Las categorías prohibidas constitucionalmente, llamadas también criterios sospechosos (sexo, religión, edad, preferencia sexual, etc.), suponen que su uso en leyes o políticas públicas está prima facie prohibido (o es sospechoso); esto significa que tomando en consideración todas las cuestiones relevantes en casos específicos, algunas veces puede justificarse el uso de alguna de estas categorías. Su uso legítimo exige una justificación adecuada que muestre que no son violatorios de derechos o que existen razones que ponderan su utilización frente a otros derechos que pueden verse afectados.

Hay que reconocer que en el proyecto de Guía se explicó muy mal el criterio de "salvar la mayor cantidad de vidas-por-completarse", pues efectivamente en el proyecto hay imprecisiones, malos ejemplos y confusión sobre este principio. ${ }^{31} \mathrm{El}$ criterio, que es ampliamente usado en el ámbito

31 En el proyecto se sostuvo, "Asignar recursos escasos de medicina critica para salvar el mayor número de vidas durante una emergencia de salud pública genera, al menos, dos dilemas. Primero, cómo asignar recursos escasos cuando dos (o más) pacientes son similares en características (i. e. edad, comorbilidades, gravedad de la enfermedad) y pronóstico médico... Segundo, cómo asignar recursos escasos cuando la prognosis es similar pero la diferencia de edad entre los pacientes es significativa. Por ejemplo, cuando solo tenemos un ventilador y hay dos pacientes: un paciente A de 80 años y un paciente B de 20 años. Supongamos que si paciente A recibe el ventilador ella vivirá 7 años más y si paciente $\mathrm{B}$ recibe el ventilador ella 
Este libro forma parte del acervo de la Biblioteca Jurídica Virtual del Instituto de Investigaciones Jurídicas de la UNAM

médico sin dejar por ello de ser polémico, supone que cuando dos personas reúnen un puntaje similar en el mecanismo de triaje, como un segundo criterio para desempatar casos se preferiría a aquél que tuviera más años de vida por completar (lo cual no necesariamente beneficia al más joven). Esto no supone entonces discriminar a los pacientes de la tercera edad, e incluso el caso a resolver podría darse entre dos pacientes de la tercera edad. Además, este principio para desempatar se utiliza cuando la diferencia de vidas (años) por completar es significativa (no una marginal).

Sin embargo, es verdad que estadísticamente el criterio sí puede llegar a traducirse en preferir al más joven (o al menos viejo), y ello lleva a pensar cuál puede ser la justificación de este criterio. En el proyecto se ofreció una justificación: se prefiere a quien perdería más años por vivir, porque el valor de la vida está en las oportunidades valiosas futuras.

Guillermo Hurtado señaló uno de los problemas con esta justificación. Atendiendo al valor meramente cuantitativo (el tiempo de vida), nos dice, pueden ofrecerse dos respuestas: la primera, la vida de alguien vale por la cantidad de años que aún tiene por vivir (teoría del valor futuro); la segunda, la vida de alguien vale por la cantidad de años que ha vivido (teoría del valor pretérito). Para la primera, por ejemplo, la muerte de un bebé o un niño es más grave que la muerte de un viejo, para la segunda es lo inverso. El utilitarismo, nos dice Hurtado, puede adoptar cualquiera de los dos puntos de vista. Pero esta aparente aporía tiene una solución, lo que él llama una teoría del valor presente, de donde resulta que cada vida vale lo mismo, pero luego reconoce que:

vivirá 65 años más... Una vida-por-completarse se debe de entender como aquella que aún no ha pasado por los diferentes estados de desarrollo bio-psico-social humanos (i.e. infancia, adolescencia, edad adulta, vejez). Y de entre las vidas-por-completarse hay que elegir aquellas que están en etapas más tempranas. Ahora, en lugar de realizar distinciones de edad de veta fina (por meses o días, por ejemplo) lo que se propone son las siguientes categorías clasificatorias: 0-12, 12-40, 41-60, 61-75, y +75. Utilizar el principio de vidas-por-completarse podría parecer injustamente discriminatorio hacia los adultos mayores, pero esto no es así. Y para entender por qué, se tendrá que remontar a la pregunta: por qué la muerte es mala para nosotros. La respuesta a esta pregunta es que la muerte es mala para nosotros porque nos priva de oportunidades valiosas futuras. Ello quiere decir que por lo general la muerte priva a los jóvenes de un número mayor de bienes que a aquellas personas que ya han pasado por dicha etapa vital. Por lo tanto, un sistema de asignación de recursos escasos que favorece salvar la mayor cantidad vidas-por-completarse es un sistema que prioriza a aquellos que por lo general perderían más si murieran”. Y más adelante se reiteraba, pero se terminaba identificando con el criterio de edad: "En caso de que exista un empate en el puntaje de priorización entre dos o más pacientes el proceso para resolverlo será el siguiente. En un primer momento se deberá de recurrir al principio vida-completa. Ello quiere decir que pacientes más jóvenes han de recibir atención de cuidados intensivos sobre pacientes de mayor edad". 
Este libro forma parte del acervo de la Biblioteca Jurídica Virtual del Instituto de Investigaciones Jurídicas de la UNAM

Se podría objetar que la teoría del valor presente no nos ayuda para decidir a quién hemos de salvar en un caso extremo: al anciano o al recién nacido. En efecto, no sirve para tomar aquella decisión. Eso no significa, sin embargo, que no sea la menos mala de las tres teorías descritas. ${ }^{32}$

Desde luego tiene razón al señalar que el criterio adoptado en el proyecto no es la única opción, ni es la única que apoyarían nuestras intuiciones. El problema es que su propuesta no puede ofrecer ninguna solución, como él mismo lo nota. De hecho, el problema es que lo que llama la teoría del valor presente está ya presupuesta en el problema: todas las vidas son valiosas, todas las personas tienen la misma dignidad, valen igual; el problema ahora es qué criterio usar en situaciones donde tenemos que elegir a quién atender en una pandemia.

El problema es difícil, pero sacándole la vuelta no se avanza. Se podría entonces estar de acuerdo con la idea de que la filosofía (la ética o la moral) no sirve para estos casos, pero no creo que Hurtado comparta esa tesis que ya discutimos en II.1. De forma que el camino es buscar algún criterio que pueda justificar una decisión difícil de este tipo. Desde luego que no sólo tenemos las opciones que refiere Hurtado, el criterio de vidas por completarse es una variación de lo que llama la teoría del valor futuro o quizá un presupuesto de esa teoría.

El criterio de salvar la mayor cantidad de vidas por completarse fue al final abandonado en la versión que se aprobó de la Guía bioética. Creo que las razones para retirarlo consistieron en reconocer que la redacción original fue defectuosa y generó la idea de que se pretendía discriminar a las personas mayores; la otra es que se consideró que incluso cuando se mejorara la redacción y se aclarara el principio, la percepción pública ya no iba a cambiar. No dejo de reconocer que el principio es polémico, se trata de un tema donde a pesar de que nuestras intuiciones pueden ser fuertes, no alcanzan para justificar un principio así. Ya hemos dicho que los números importan moralmente, pero tampoco esto significa que sean decisivos siempre, y cuando las decisiones implican, además, diferencias marginales, ni siquiera es obvio que deban contar. Este también fue un problema del proyecto cuando presentó una segmentación de edades para "facilitar" la toma de decisiones.

Ruth Macklin, experta en bioética, advirtió precisamente estos problemas en la Guía y celebró que se hubiera retirado el criterio de vidas por

32 Gillermo Hurtado, “¿Hay vidas que valen más que otras?”, La Razón, 25 de abril de 2020, consultable en: https://wwre.razon.com.mx/opinion/guillermo-hurtado-hay-vidas-que-valen-masque-otras/. 
Este libro forma parte del acervo de la Biblioteca Jurídica Virtual del Instituto de Investigaciones Jurídicas de la UNAM

completarse. ${ }^{33}$ Sin embargo, sus argumentos no me parecen contundentes. El tema del valor de la vida es fundamental en bioética, pues más allá de la situación que se prevé en la Guía bioética, existen otros muchos contextos donde este tipo de decisiones se toman (trasplantes de órganos, diálisis, situaciones de desastre, etc.). En este sentido la discusión sobre la relevancia moral de la edad es un tema estrechamente relacionado. Por lo general, todos valoramos nuestra vida y valoramos el tiempo que nos resta por vivir sin importar la edad que tengamos. Sin embargo, quizá una intuición mayoritaria sea que pierde más quien puede vivir más y pierde menos quien menos tiempo puede vivir. Vivimos comúnmente como más trágica la pérdida de la vida de una niña, que la de una mujer anciana (quizá con independencia de los años que le resten por vivir a cada una). La intuición se apoya en la idea de que normalmente consideramos que hay una edad que representa un umbral de lo que significa haber vivido una vida razonable (en términos cuantitativos, no cualitativos). Por ejemplo, si pensamos que ese umbral está en los 70 años, consideramos que quienes no llegaron a tal edad vieron truncada de manera injusta su vida, mientras que quienes viven más son afortunados por vivir más tiempo.

Pero el argumento contra la edad afirmaría que la edad nunca puede ser un criterio relevante de decisión en este tipo de situaciones, o como afirma Macklin, no puede ser un criterio de justicia o equidad (fairness). Desde luego que usar un criterio de edad puede ser problemático en muchos casos, especialmente cuando las diferencias son marginales, supongamos que un paciente tiene una expectativa de vida de 30 años y otro una de 29; en este tipo de casos nuestras intuiciones sobre preferir a quien tiene la expectativa de vida mayor no parecen ser muy convincentes. Tampoco serían definitivas al evaluar si una persona vivió o no una vida razonable, por ejemplo, si una muere a los 69 y otra a los 71 años. En este sentido, acepto que el que Guía haya establecido rangos de edad (ver nota 32) fue un error.

Sin embargo, aún podríamos decir — siguiendo a John Harris-, que mientras siempre es desafortunado que alguien muera cuando quiere seguir viviendo, no es una tragedia morir a una edad avanzada; pero siempre que alguien muere prematuramente además de ser desafortunado es una tragedia. ${ }^{34}$ Aunque "edad avanzada" y "prematuramente" son conceptos vagos, conviene dejarlos así, pues el argumento nos sirve cuando personas razonables pueden estar de acuerdo que estos conceptos se aplican a la situación

33 Véase Macklin, Ruth, "Allocating medical resources fairly. The CSG bioethics guide", en Salud Pública de México, 62, consultable en: https://doi.org/10.21149/11486.

34 Véase Harris, John, The Value of Life, Routledge, Londres-Nueva York, 1985, p. 93. 
Este libro forma parte del acervo de la Biblioteca Jurídica Virtual del Instituto de Investigaciones Jurídicas de la UNAM

en cuestión, cuando no (si la diferencia por ejemplo es marginal), entonces el argumento contra la edad se volvería relevante. ${ }^{35}$

Usar como argumento en contra de uso del criterio de la edad, que es posible que alguien joven muera antes que una persona mayor, o que alguien a quien se le da prioridad porque se espera viva más que otro, podría morir de un accidente al día siguiente, etc., no me parecen argumentos pertinentes para dejar de usar criterios generales, pues a todo criterio o norma general se le aplicaría entonces este tipo de salvedades para impugnarlos.

Queda entonces abierto el tema de si usar la edad es o no un criterio discriminatorio en situaciones de este tipo. Yo acepto que, en principio, hay que revisar a fondo este tipo de criterios, que se trata de criterios sospechosos, pero que pueden tener el algunas circunstancias una adecuada justificación.

\section{El azar como criterio}

Precisamente como es difícil justificar criterios ulteriores para preferir a las personas que deben ser tratadas, otra de las opciones comunes en la práctica de triaje es usar un criterio de azar (volado, sorteo, etcétera). Pero a muchos les pareció un insulto, una falta de respeto al valor de la vida, que se considerara esta posibilidad. En ocasiones parece que lo que ofendía era el lenguaje, que se hablara de "echar un volado".

Tanto en el proyecto como en la versión final, la decisión por medio del azar se plantea como un último recurso frente a situaciones donde los otros criterios no sirvan para decidir a quién priorizar. El azar en este sentido es un procedimiento equitativo e imparcial, y en vista de no poder recurrir a algún otro criterio, se considera un procedimiento imparcial para decidir a quién se va a priorizar. ${ }^{36}$ La utilización del azar como criterio sería criticable si se propusiera como medida principal para tomar este tipo de decisiones, quizá muchos que criticaron la Guía no advirtieron que no se proponía como primer método de decisión, ni como segundo, ni tercero, era un último criterio. Quien diga que "echar volados" es una falta de respeto al gremio médico y a la vida humana, tendría que ofrecer algún argumento.

\section{Ibidem, p. 94.}

36 Véase Ortiz Millán, Gustavo, "La Guía Bioética, la equidad y el criterio de aleatoriedad”, Este País, 24 Abril de 2020, consultable en: https://estepais.com/tendencias_y_opiniones/ la-guia-bioetica-la-equidad-y-el-criterio-de-la-aleatoriedad/; también González Placencia, Luis, "La Guía Bioética versión 30.04.20”, Animal Político, 2 mayo de 2020, consultable en: https:// wrere.animalpolitico.com/phronesis/la-guia-bioetica-version-30-04-20/. 
Este libro forma parte del acervo de la Biblioteca Jurídica Virtual del Instituto de Investigaciones Jurídicas de la UNAM

Paulina Rivero, por ejemplo, sostuvo que antes de usar este criterio todavía quedaban algunas otras formas racionales de decidir, como considerar los deseos de vivir de un paciente, su estado anímico, si tenía dependientes económicos o considerar si tiene quién le cuide al salir del hospital. ${ }^{37} \mathrm{El}$ problema, como ya advertimos, es si es razonable que un comité de triaje esté posibilitado para utilizar estos criterios. Pero, supongamos sin conceder que pueda usarlos, qué pasaría si tales criterios entran en conflicto, que los dos pacientes tienen el mismo número de dependientes; o uno tiene dependientes y el otro no pero el otro, pero éste último tenga más deseos de vivir que el otro (suponiendo que ello peda determinarse). Nuevamente tendríamos un empate, ¿qué sigue entonces?, ¿echarse un volado sería una falta de respeto por la vida? La única alternativa sería decidir por algún otro criterio arbitrario.

Al final, tanto el proyecto de Guía como la versión corregida que fue aprobada, contemplan distintos principios y criterios que han de considerarse: salvar el mayor número de vidas, el principio de necesidad, la probabilidad de supervivencia, priorizar al personal de salud que se enfrenta a la pandemia, atender a información científica que puede resultar relevante, priorizar a personas que pertenecen a grupos vulnerables ${ }^{38} \mathrm{y}$, finalmente, decidir en caso extremo por azar.

Frente a la ausencia de otros criterios que pudieran ser relevantes en situaciones como las que se están contemplando (hemos ya descartado la pertinencia de considerar cuestiones cualitativas en estas circunstancias), decidir al azar se torna equitativo y una forma de evitar que se introduzcan prejuicios y se discrimine a las personas.

Queda mucho por seguir discutiendo y por profundizar. Es importante que temas como éstos se discutan en foros públicos, como fue discutida esta Guía, la calidad de los debates siempre puede mejorar, los filósofos y demás expertos deberíamos ser capaces de elevar los niveles de discusión. A veces ello no se consigue porque se politiza la discusión y porque, peor aún, se discute con mala fe, se pretende derrotar a un adversario a costa de distorsionar lo que dice, o se busca atribuirles la peor interpretación

37 Rivero Weber, Paulina, "La Guía Bioética”, Milenio, 20 de abril de 2020, consultable en: https://wrere.milenio.com/opinion/paulina-rivero-weber/el-desafio-del-pensar/la-guia-bioetica.

38 En la última versión de la Guía, se introdujo por sugerencia de organismos como la CDHCDMX, la Copred y Conapred, los criterios que la Comisión Interamericana de Derechos Humanos consideró respecto de la atención a personas que pertenecen a grupos vulnerables, y que publicó en la Resolución 1/2020, Pandemia y Derechos Humanos en las Américas, 10 de abril de 2020, consultable en: http://oas.org/es/cidh/decisiones/pdf/Resolucion1-20-es.pdf. 
Este libro forma parte del acervo de la Biblioteca Jurídica Virtual del Instituto de Investigaciones Jurídicas de la UNAM

posible a sus afirmaciones. La deliberación en una democracia desde luego implica confrontación política de ideas, pero si los actores no se conducen con buena fe es imposible que la deliberación tenga algún valor. Personalmente estoy agradecido con quienes, sin importar si estuvieron a favor o en contra del proyecto, lograron presentar razones y argumentos, incluso dejar preguntas abiertas; eso es lo que enriquece y fortalece una decisión o una política pública. 